\section{Meningitis bacteriana por Streptococcus pneumoniae con ADA extraordinariamente elevada}

\section{Bacterial meningitis with extraordinarily high ADA due to Streptococcus pneumoniae}

\section{Sr. Director:}

Aunque el diagnóstico microbiológico de la meningitis resulta primordial, en la mayor parte de las ocasiones se administra de forma inicial un tratamiento empírico basado en los microorganismos más probables según el análisis bioquímico del líquido cefalorraquídeo (LCR).

Presentamos el caso de una paciente de 12 años, que ingresó en la $\mathrm{UCl}$ por alteración del nivel de conciencia. Era natural de Perú y estaba correctamente vacunada. Vivía en España con sus padres desde hacía 2 años y no tenía antecedentes relevantes.

En la semana previa, la paciente había presentado clínica catarral con fiebre y cefalea tratada previamente con paracetamol y 3 dosis de amoxicilina. En las $4 \mathrm{~h}$ previas a su ingreso en la $\mathrm{UCl}$ comenzó con fluctuación del nivel de conciencia, verborrea incoherente y dolor cervical. En la exploración física estaba afebril y tenía unas constantes vitales estables. Estaba obnubilada, obedecía órdenes y los signos meníngeos (Kernig y Brudzinski) eran positivos. El resto de la exploración neurológica era normal y no presentaba petequias.

En el hemograma se obtuvieron 19.700 leucocitos (el 84\% polimorfonucleados, el $4 \%$ linfocitos y el $6 \%$ cayados). El resto resultó normal. En la bioquímica no había datos relevantes, salvo PCR de $26,6 \mathrm{mg} / \mathrm{dl}$ y procalcitonina de $13,84 \mathrm{ng} / \mathrm{ml}$ (sanos <0,5 $\mathrm{ng} / \mathrm{ml}$ ).

Se realizó una TAC craneal sin administración de contraste en la que únicamente destacaba una ocupación parcial de celdillas etmoideas, senos maxilares, esfenoidales y frontales, todo ello indicativo de pansinusitis (fig. 1). Se realizó luego una punción lumbar y se obtuvo un LCR de aspecto claro: glucosa inferior a $5 \mathrm{mg} / \mathrm{dl}$; proteínas totales de $63 \mathrm{mg} / \mathrm{dl}$; 90 hematíes y 470 células $/ \mathrm{mm}^{3}$ (el $85 \%$ polimorfonucleares y el $15 \%$ mononucleares); destacaba la ADA de $28 \mathrm{U} / \mathrm{l}$ (normal $<6 \mathrm{U} / \mathrm{l}$ ).

A pesar del alto valor de ADA en el LCR (se repitió en otro laboratorio y se obtuvo un valor similar) no consideramos demasiado probable la etiología tuberculosa (buena respuesta al tratamiento empírico iniciado con ceftriaxona, vancomicina y aciclovir), por lo que no se inició tratamiento antituberculoso a la espera del cultivo microbiológico. Tres días después se recibió el cultivo en el LCR de Streptococcus pneumoniae sensible a penicilina y cefalosporinas.

El incremento del valor de ADA en el LCR es una importante pista diagnóstica de la meningitis tuberculosa y de la neurobrucelosis. Aunque no hay un consenso con respecto al valor normal de ADA, varios estudios retrospectivos indican que una concentración mayor de 9 o $10 \mathrm{U} / \mathrm{l}$ en el LCR es muy sensible y específica para el diagnóstico de meningitis tuberculosa o de neurobrucelosis ${ }^{1}$. Además de las etiologías mencionadas, la ADA puede estar elevada en la

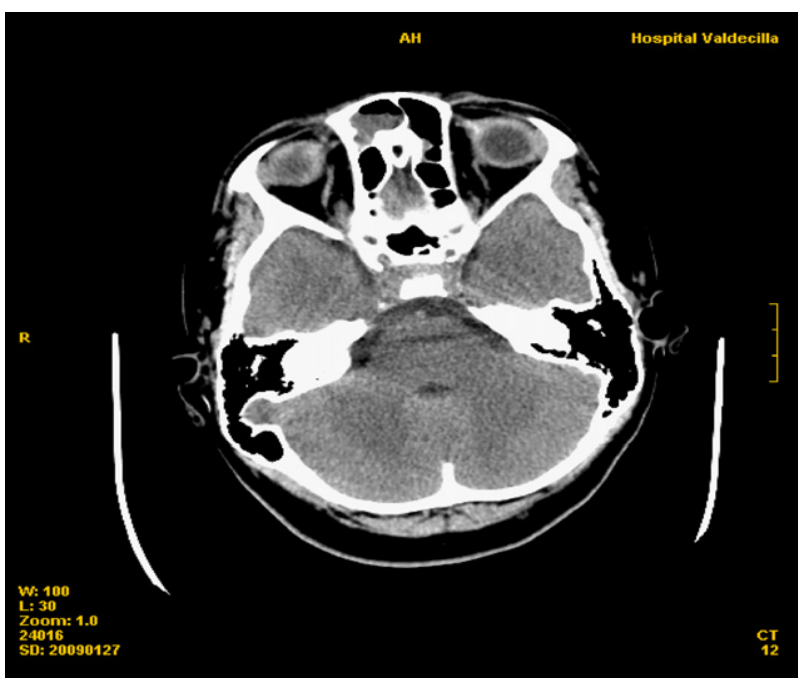

Figura 1 TC craneal realizada a la paciente, en al que únicamente destacaba la ocupación de los senos etmoidales y esfenoidales.

meningitis sarcoidea ${ }^{2}$, la infiltración meníngea por leucemia o linfoma ${ }^{3}$, la toxoplasmosis cerebral, el infarto cerebral ${ }^{3}$, la meningitis criptocócica, la neurosífilis y otras meningitis asépticas ${ }^{4}$. Recientemente se ha descrito un caso de meningitis por Listeria con ADA elevada $(12,3 \mathrm{U} / \mathrm{l})^{5}$. Los mecanismos exactos de esta elevación no están claros, pero se ha postulado la implicación de la oligodendroglia y las células endoteliales o la síntesis intratecal en respuesta a antígenos bacterianos ${ }^{1}$.

Nuestro caso de meningitis por $S$. pneumoniae con ADA extraordinariamente elevada en una paciente de edad pediátrica ilustra la prudencia con la que deben interpretarse determinados marcadores bioquímicos y muestran las limitaciones que a veces presentan.

\section{Bibliografía}

1. López-Cortés LF, Cruz-Ruiz M, Gómez-Mateos J, Jiménez-Hernández $\mathrm{D}$, Jiménez-Mejías $\mathrm{E}$, Pachón $\mathrm{J}$, et al. Adenosine deaminase activity in the CSF of patients with aseptic meningitis: Utility in the diagnosis of tuberculous meningitis or neurobrucellosis. Clin Infect Dis. 1995;20:525-30.

2. García-Monco C, Berciano J. Sarcoid meningitis, high adenosine deaminase levels in CSF and results of cranial irradiation. J Neurol Neurosurg Psychiatry. 1988;51:1594-6.

3. Pettersson T, Klockars M, Weber TH, Somer H. Diagnostic value of cerebrospinal fluid adenosine deaminase determination. Scand J Infect Dis. 1991;23:97-100.

4. Machado LD, Livramento JA, Spina-Franca A. Adenosine deaminase in the cerebrospinal fluid of patients with acquired immunodeficiency syndrome. Arq Neuropsiquiatr. 1995;53:755-9.

5. Nishida $\mathrm{Y}$, Komachi $\mathrm{H}$, Mizusawa $\mathrm{H}$. A case of Listeria meningitis associated with increased adenosine deaminase in cerebrospinal fluid. Diagn Microbiol Infect Dis. 2007;57:435-7.

M.J. Domínguez Artiga ${ }^{a}$, M.S. Holanda Peña ${ }^{a}$, J. Velasco Montes $^{\text {b,* }}$, R.M. Orozco Abril ${ }^{\mathrm{c}}$ y J.L. Teja Barbero ${ }^{\mathrm{a}}$ 


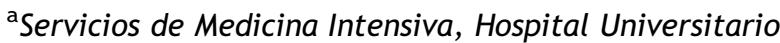
Marqués de Valdecilla, Santander, España

${ }^{\mathrm{b}}$ Medicina Interna, Hospital Universitario Marqués de

Valdecilla, Santander, España

'Análisis Clínicos, Hospital Universitario Marqués de Valde-

cilla, Santander, España

doi:10.1016/j.medin.2009.03.003
*Autor para correspondencia.

Correo electrónico: javier_velasco_montes@hotmail.com (J. Velasco Montes). 